\title{
A INCLUSÃO EDUCACIONAL DE PESSOAS COM DEFICIÊNCIA NAS UNIVERSIDADES FEDERAIS SOB A PERSPECTIVA DA LEI 13.409/2016
}

\author{
Lorena Ismael Fernandes ${ }^{1}$
}

\begin{abstract}
Resumo
A educação inclusiva visa ampliar a participação de todos os estudantes no ensino regular, garantindo o exercício da cidadania. No ensino superior, a Lei 13.409/2016 cria uma reserva de vagas às pessoas com deficiência, advindas de escola pública, nas universidades públicas federais. O presente artigo busca compreender como o acesso impulsionado pela legislação mobiliza políticas e instrumentos de permanência estudantil e quais são os obstáculos encontrados para a efetivação dessa política no meio acadêmico. Além disso, apresentam-se ferramentas que podem auxiliar o processo educacional inclusivo nas universidades, como a Tecnologia Assistiva, e discute-se o papel da universidade na expansão e consolidação das práticas inclusivas. De acordo com os levantamentos bibliográficos realizados, é notória a importância de uma ação afirmativa na promoção da democratização do ensino, porém é observado que o sucesso da política está relacionado a utilização de mecanismos ao longo da trajetória universitária que permitam a inclusão educacional em sua totalidade.
\end{abstract}

Palavras-chave: educação inclusiva, Lei n ${ }^{0}$ 13.409/2016, universidade, acesso, permanência.

\begin{abstract}
Inclusive education aims to increase the participation of all students in regular education, ensuring the exercise of citizenship. In higher education, Law 13.409/2016 creates a reserve of vacancies for people with disabilities, coming from public schools, in federal public universities. This article tries to understand how the access impelled by the legislation stimulates policies and instruments of student permanence and what are the obstacles found for the accomplishment of this policy in the academic environment. In addition, devices that can aid the inclusive educational process in universities are presented, such as Assistive Technology, and discuss the university's role in expanding and consolidating inclusive practices. According to the specialized literature, the importance of affirmative action in the promotion of the democratization of education is notorious, but it is observed that the success of the policy is related to the use of mechanisms along the university trajectory that allow the educational inclusion in totality.

Keywords: inclusive education, Law 13.409/2016, university, access, permanence.
\end{abstract}

\footnotetext{
${ }^{1}$ Universidade Federal do ABC. E-mail: lorena.ismae198@gmail.com 


\section{Introdução}

O debate contemporâneo sobre a importância da representatividade e da entrada de segmentos populacionais, historicamente, marginalizados no ambiente educacional é um dos temas mais relevantes no cenário brasileiro. A pluralidade compartilhada na dimensão sócio educacional não diz respeito, obrigatoriamente, ao debate sobre as minorias, mas ao coletivo, que revela em seu ponto central as diferenças individuais, tratando da necessidade de oportunidade, adequações, flexibilidade e, principalmente, ao respeito às dificuldades e limitações (FERREIRA, 2007).

A educação inclusiva, conceito fundamental para se compreender como tal processo está sendo desenvolvido, visa contemplar as demandas que são apresentadas por diferentes necessidades decorrentes de condições individuais (por exemplo, as deficiências), econômicas ou socioculturais, (FERRARI, SEKKEL, 2007), e tem como função a promoção do exercício da cidadania e a garantia dos direitos para todos.

O movimento em prol dos direitos das pessoas com deficiência (PcD), grupo selecionado para a pesquisa, ganhou notoriedade mundial em meados da década de 1980 com o Programa de Ação Mundial para as Pessoas Deficientes (PAM) promovido pela Organização das Nações Unidas, que buscava a promoção da "igualdade" e "participação plena" na sociedade e no desenvolvimento. No Brasil, o governo federal possui uma postura de investimento gradativo na educação inclusiva. No tocante ao ensino superior, a criação de instituições e normas legais respaldaram o estímulo a inclusão de pessoas com deficiência: o Conselho Nacional de Educação (CNE), ao estabelecer as diretrizes nacionais para a educação especial, registram, no Parecer CNE/CEB no 17, de 03 de julho de 2001 e a Resolução CNE/CEB nº 02, de 11 de setembro de 2001, que os sistemas de ensino devem matricular qualquer educando com necessidades educacionais especiais. O Ministério da Educação (MEC) estabelece em 2003 a Portaria 3.284/2003 que indica as exigências de acessibilidade para instruir processos de autorização e de reconhecimento de cursos e credenciamento de instituições (MEC, 2003).

Dada essa conjuntura, as universidades começam a se organizar para propiciar a inclusão de PcD, permitindo que a inclusão escolar alcançada na Educação Básica tenha uma continuidade. A ação mais significativa na estruturação do processo de inclusão de pessoas com deficiência nas instituições públicas federais de ensino superior no Brasil aconteceu por meio da Lei $n^{\circ}$ 13.409/2016, que decreta a inclusão de PcD advindas de escola pública na Lei de Cotas - 
Lei $\mathrm{n}^{\mathrm{o}}$ 12.711/2012 - fundando uma nova dinâmica nacional no sentido de ampliar e democratizar o espaço universitário a um grupo que não tiveram seus direitos assegurados por um longo período.

A Lei $n^{\circ}$ 13.409/2016 garante o acesso, porém, para que a política afirmativa obtenha sucesso, é necessário oferecer igualmente condições de permanência aos estudantes. O presente estudo busca entender como o acesso impulsionado pela legislação mobiliza políticas e instrumentos de permanência e quais são os obstáculos encontrados para a efetivação da educação inclusiva nas universidades federais, apresentando possíveis meios para se atingir resultados positivos, como o uso da Tecnologia Assistiva e de estratégicas pedagógicas, por exemplo, o Plano Educacional Individualizado (PEI). Dentro dessa discussão, levanta-se a questão: qual é o papel das universidades públicas, através das bases de ensino, pesquisa e extensão, na expansão e consolidação da política inclusiva? Por fim, o vínculo entre o ambiente acadêmico e sociedade civil será abordado com intuito de demonstrar como a troca entre eles constrói e aprimora ações e técnicas na educação inclusiva.

\section{LEI No 13.409/2016 - inserção de PcD na lei de cotas}

A inclusão de PcD em universidades federais com garantia legal a reserva de vagas específicas aconteceu por meio de um decreto presidencial em 28 de dezembro de 2016, alterando em termos a Lei de Cotas - Lei n 12.711 , de 29 de agosto de 2012:

Art. $1^{\circ}$. As instituições federais de educação superior vinculadas ao Ministério da Educação reservarão, em cada concurso seletivo para ingresso nos cursos de graduação, por curso e turno, no mínimo $50 \%$ (cinquenta por cento) de suas vagas para estudantes que tenham cursado integralmente o ensino médio em escolas públicas. (BRASIL, 2012).

Para o objeto de análise deste estudo, o artigo $3^{\circ}$ presente na Lei de Cotas citada será explorado com maior profundidade, que decreta originalmente:

Art. $3^{\circ}$. Em cada instituição federal de ensino superior, as vagas de que trata o art. $1^{\circ}$ desta Lei serão preenchidas, por curso e turno, por autodeclarados pretos, pardos e indígenas, em proporção no mínimo igual à de pretos, pardos e indígenas na população da unidade da Federação onde está instalada a instituição, segundo o último censo do Instituto Brasileiro de Geografia e Estatística (IBGE). (BRASIL, 2012)

Trata-se uma política afirmativa efetivada pelo governo brasileiro com o objetivo de corrigir uma desigualdade, no caso, racial presente na sociedade, acumulada ao decorrer do 
tempo - a existência de um racismo estrutural e institucionalizado (ONUBR, 2013). As políticas de ações afirmativas têm como foco, justamente, determinados grupos, visando promover igualdade de oportunidade. Na educação, seu objetivo é oferecer a possibilidade de disputar certas vagas no ensino superior a indivíduos que não teriam a chance de acessar a universidade inicialmente, sendo uma relevante conquista social para o país (DIAS; DA COSTA, 2016).

As ações afirmativas se distinguem das políticas puramente antidiscriminatórias por atuar de maneira preventiva em favor de indivíduos que possivelmente são discriminados, o que pode ser entendido tanto como uma prevenção à discriminação quanto como uma reparação de seus efeitos (GRUPO DE ESTUDOS MULTIDISCIPLINARES DA AÇÃO AFIRMATIVA, 2015). A ação afirmativa não tem que ser interpretada como um benefício ou um mecanismo de injustiça perante aos outros candidatos, mas, ao contrário, pois somente se faz necessária quando identifica um histórico de injustiças e direitos que não foram assegurados.

Como supracitado, a inclusão do grupo de PcD ocorreu através da Lei no 13.409/16 e modifica em termos os artigos $3^{\circ}, 5^{\circ}$ e $7^{\circ}$ da Lei $N^{o} 12.711 / 12$, cabendo a exposição do artigo $3^{\circ}$ :

Art. $3^{\circ}$. Em cada instituição federal de ensino superior, as vagas de que trata o art. $1^{\circ}$ desta Lei serão preenchidas, por curso e turno, por autodeclarados pretos, pardos e indígenas e por pessoas com deficiência, nos termos da legislação, em proporção ao total de vagas no mínimo igual à proporção respectiva de pretos, pardos, indígenas e pessoas com deficiência na população da unidade da Federação onde está instalada a instituição, segundo o último censo da Fundação Instituto Brasileiro de Geografia e Estatística - IBGE. (BRASIL, 2016).

O apoio legal em prol das pessoas com deficiência foi fortalecido de maneira expressiva no ano de 2016. Além da inclusão na Lei de Cotas, a Lei Brasileira de Inclusão da Pessoa com Deficiência (Estatuto da Pessoa com Deficiência), Lei $\mathrm{n}^{\circ}$ 13.146/2016 foi sancionada para assegurar os direitos das pessoas com deficiência, com ênfase na promoção de igualdade de oportunidades, de autonomia e garantia de acessibilidade no país. Em um capítulo dedicado ao direito à educação, é garantido pelo poder público o "aprimoramento dos sistemas educacionais, visando a garantir condições de acesso, permanência, participação e aprendizagem, por meio da oferta de serviços e de recursos de acessibilidade que eliminem as barreiras e promovam a inclusão plena" (BRASIL, 2016), entre outros dispositivos que reforçam o processo de inclusão.

A entrada de estudantes com deficiência no ensino superior é um grande avanço, no entanto, nota-se que a presença do indivíduo em sala de aula não significa a sua participação plena no espaço universitário (TOMELI et al., 2018). Para possibilitar a efetividade da inclusão, 
é preciso que haja mecanismos de auxílio que criem condições reais de permanência dadas as necessidades particulares que cada deficiência demanda; sem o apoio institucional haverá, na verdade, um processo de exclusão dos estudantes que adentraram nas universidades através da política afirmativa, não atingindo o objetivo final de democratizar e incluir no nível superior.

\section{Educação inclusiva}

Segundo Ferreira (2007), o processo de inclusão acontece a partir da organização e implementação de soluções educativas que suprimam as limitações e dificuldades, com ações voltadas a práticas que reforçam a apropriação do saber, do saber fazer e do exercício crítico pessoal; envolve também a eliminação das barreiras arquitetônicas e, principalmente, as atitudinais, que são as percepções do público leigo - aqueles que não têm contato com a temática que abarca as questões inclusivas.

De acordo com o Decreto 3.298/1999, a deficiência é considerada "toda perda ou anormalidade de uma estrutura ou função psicológica, fisiológica ou anatômica que gere incapacidade para o desempenho de atividade, dentro do padrão considerado normal para o ser humano" (BRASIL, 1999). Tais perdas ou anormalidades geram necessidades especiais - no campo que está sendo tratado, necessidades educacionais especiais - que não são atendidas com as práticas de normalização e integração, princípios que guiam o projeto educacional brasileiro com o uso de currículos padronizados, tradicionais e fragmentados (CAMARGO, SOFFA, MARKOWICZ, 2017). Cada estudante com deficiência apresenta suas particularidades devido a sua condição, dessa forma, não é possível falar em características gerais do grupo. É claro que é possível identificar indivíduos em situações similares que acabam compartilhando de mesmas necessidades, como, por exemplo, os deficientes auditivos, que requerem intérpretes de libras, mas é necessário entender que a construção de uma educação inclusiva é focada na individualidade de cada estudante, e em alguns casos, essas necessidades podem ser semelhantes e serem resolvidas de forma conjunta.

A definição do conceito de educação inclusiva pode ser apresentada de diversas maneiras, mas, em sua essência, dialogam com igualdade de significados. A educação inclusiva implica o reconhecimento e o atendimento das necessidades particulares de cada estudante, "adaptando-se aos vários estilos e ritmos de aprendizagem, de modo a garantir uma educação de qualidade para 
todos por meio de currículos adaptados e adequados, [...] de estratégias pedagógicas" (TOMELI et al., 2018, p. 95).

O acesso é o passo inicial de uma inclusão educacional, que é um processo amplo e complexo que deve acontecer de maneira contínua, no qual as mudanças são gradativas e construídas a partir da coletividade e colaboração. A Lei 13.409/2016 por si não consegue produzir resultados que promovam a inclusão desse grupo, é necessário articular mecanismos e estratégias que possam garantir a realização do ciclo educacional completo: acesso, permanência e conclusão.

\section{Desafios e dificuldades no processo inclusivo}

A Lei $n^{\circ} 13.409 / 16$ está inserindo um grupo muito específico de estudantes que necessita de assistências e amparos diferenciados, como foi explicado na seção anterior, em instituições que não estão habituadas a lidar e oferecer o apoio fundamental a eles.

É importante ressaltar que o ingresso de alunos com necessidades especiais muitas vezes não ocorrerá de modo explícito, mesmo com a presença de cotas para $\mathrm{PcD}$. O primeiro fator é que a lei somente abrange alunos oriundos de escolas públicas, fazendo com que o ingresso de estudantes com deficiência advindos de escolas particulares aconteça pela seleção de "ampla concorrência" em casos pontuais. O segundo fator, que é observado com frequência nas universidades, é que as dificuldades podem se revelar depois da entrada do aluno na instituição, sendo percebidas pela classe, docentes e coordenação aos poucos. Há situações em que o próprio discente desconhece sua condição ou não tem consciência das suas dificuldades, como o caso da estudante que descobriu o diagnóstico de dislexia por meio de conteúdos vistos nas aulas de neurociência (FERRARI, SEKKEL, 2007).

Levantamentos realizados por Silva et al. (2012) demonstraram que as principais dificuldades encontradas para o sucesso da educação inclusiva são o despreparo dos professores, a falta de conhecimento da população universitária em geral, estratégias pedagógicas falhas e limitações físicas. A falta de conhecimento e o despreparo dos docentes são apontadas na literatura como um dos principais problemas que impedem o avanço inclusivo nas escolas e universidades; para Pletsch (2009), isso está associado a uma defasagem na formação e capacitação desses profissionais. É notado pela autora que ainda há uma crença que os estudantes 
com deficiência não são capazes de se desenvolver como os demais alunos e agir autonomamente - importância da remoção das barreiras atitudinais.

Como assinala Bueno (1999), os professores regulares não costumam ter contato com essa categoria de alunos e a sua formação, mesmo que seja em cursos da licenciatura ou Pedagogia, não possibilita o aprendizado em habilidades voltadas as necessidades educacionais especiais. O cenário é agravado ao se considerar os problemas estruturais da educação no país que contam com altos índices de evasão, turmas superlotadas e, mais recentemente, cortes agressivos na verba destinada as universidades públicas federais.

A pesquisa feita por Michels (2000) fortalece os pontos indicados pela produção teórica especializada comprovando que os alunos já inseridos no meio universitário consideram prioritária a adaptação do ambiente físico e a implantação de centros de apoio para o desenvolvimento de técnicas e recursos inclusivos, sendo avaliada também, a dimensão psicossocial, expondo os relatos de preconceito que sofrem nas universidades. Segundo Sassaki (2002), existem seis modalidades básicas de acessibilidade: arquitetônica, comunicacional, metodológica, instrumental, programática e atitudinal, com a tecnológica permeando todas elas. O exercício de cada modalidade, que abrange em si características próprias, precisa ser objetivo central das instituições de ensino para a efetivação da inclusão educacional.

\section{O papel das universidades na expansão e consolidação das práticas educacionais inclusivas}

$\mathrm{O}$ artigo "O papel da universidade frente às políticas públicas para educação inclusiva" escrito por Rosana Glat e Márcia Denise Pletsch (2004) elucida a importância e a função da universidade na produção de conhecimentos e na elaboração de políticas voltadas a inclusão com base nos três pilares que compõe o meio acadêmico: ensino, pesquisa e extensão. As autoras defendem que a escola inclusiva, modelo que pode ser empregado, em termos, nas universidades, ainda não existe, logo, as universidades devem contribuir e liderar o processo de construção.

O ensino, eixo primordial das universidades, diz respeito a formação de capital humano, aspecto fundamental para o sucesso de uma política de inclusão educacional, já que é responsável pela capacitação dos futuros profissionais. Segundo o texto, para se enfrentar a realidade de despreparo dos funcionários envolvidos na educação, é necessário que a universidade seja capaz de formar dois tipos de educadores: um direcionado ao ensino regular, capacitados com o nível de conhecimento desejável e com habilidade relacionada ao alunado diversificado, e o outro com 
especialização nas necessidades educacionais especiais que os estudantes podem apresentar, com uma formação apropriada a função que será exercida. É importante ressaltar que esse trabalho carece de ser cumprido em conjunto, de forma a não provocar surgimento de ações segregacionistas, isto é, deve-se manter um nível elevado de interação entre os estudantes sem necessidades especiais e os estudantes com deficiência, ao contrário, haverá uma separação prejudicial na forma como se dá o processo de aprendizagem entre os dois grupos, podendo ocorrer um isolamento dos estudantes com deficiência devido as suas necessidades.

O segundo eixo de atuação das universidades é a pesquisa. No campo da educação, as pesquisas aplicadas contribuem expressivamente para análise e mudança da realidade. Glat e Pletsch (2004) concordam que o foco das pesquisas tem que ser direcionado em torno de dois pontos: no primeiro, deve-se utilizar pesquisas de campo, com diferentes metodologias, para entender as diferentes experiências sobre inclusão e segundo, é preciso valorizar pesquisas com abordagens inovadoras que possam responder demandas do cotidiano na vida escolar - e na vida universitária também. A combinação de teoria e prática quebra o paradigma de separação entre academia e campo, integrando a comunidade externa e o ambiente universitário. Como o processo ocorre dentro da universidade, a partir da sua orientação, há uma maior facilidade em aplicar esses conhecimentos na realidade acadêmica, apropriando-se das suas descobertas e repassando para redes escolares posteriormente; ou seja, o processo inclusivo educacional deve ser pioneiro nas universidades, servindo como referência para outros setores educacionais. De maneira inversa, é possível que a universidade observe casos inclusivos de sucesso em outras áreas e incorpore em suas práticas através de levantamentos e estudos.

Essas experiências refletem a terceira esfera de atuação, que é a extensão: ações que articulam a atuação entre a universidade e os aprendizados sociais do público e instituições externas. $\mathrm{O}$ desempenho e resultados para ambos os atores são bastante favoráveis, afetando a eficiência e efetividade das políticas educacionais inclusivas.

Em síntese, as universidades devem assumir a responsabilidade de formar e capacitar professores e profissionais ligados a educação com uma perspectiva inclusiva. Assim como deve fomentar pesquisas e projetos que analisem, produzam e difundam aspectos e ações voltadas a essa área. 


\section{Estratégias para a efetivação de práticas inclusivas}

Ainda que haja inúmeras barreiras a serem superadas, é verificado, atualmente, a existência de estratégias que podem atender as necessidades educacionais especiais e que são facilitadoras no processo de inclusão. Uma das principais ferramentas é o uso da Tecnologia Assistiva (TA), que corresponde ao agrupamento de técnicas, dispositivos e processos que ampliam as aptidões dos estudantes com deficiência e melhoram sua trajetória de aprendizagem; para isso, baseiam-se em ações de caráter multidisciplinar e requer a participação de profissionais de diversas áreas (FACHINETTI; CARBONE CARNEIRO, 2017). A TA estimula a troca entre docentes e estudantes no processo de encontrar as funcionalidades e recursos adaptados que mais otimizam as habilidades da pessoa com deficiência (GONÇALVES, 2010). Cabe as instituições investir nesses serviços para gerar um maior bem-estar dos estudantes, aumentando suas chances de permanecer na universidade.

Dentre as estratégias pedagógicas mais comuns para adaptar o conteúdo curricular para aqueles estudantes que necessitam, está o Plano Educacional Individualizado (PEI). O PEI favorece o desenvolvimento acadêmico e inclusão educacional através das características singulares de cada estudante. Esse instrumento avalia a condição e necessidades físicas, tecnologias, entre outras, do estudante e permite traçar metas para se atingir objetivos específicos para o aluno (MASCARO, 2018). Devido ao seu caráter individualizado, torna-se um desafio para o professor, por exemplo, utilizar o PEI em turmas de ensino comum com muitos alunos (CAPELLINI, RODRIGUES, 2014).

$\mathrm{O}$ aumento do número de estudantes com necessidades especiais demandará, na mesma proporção, maior uso e aplicação desses mecanismos, encontrando dificuldades para se expandir, pois o atendimento exige uma execução individualizada, sendo necessária a mobilização de diversos profissionais e, consequentemente, investimento orçamentário nessa área. Por essa razão, a educação inclusiva precisa ser entendida como um intermédio para a concretização de direitos, com foco na equidade, e não como uma política pública voltada a retornos financeiros futuros.

Em termos mais objetivos, o sucesso da política afirmativa em questão abarca procedimentos de criação de centros de apoio pedagógico, de viabilização de intérpretes e instrutores de libras, acessibilidade à comunicação, aquisição de materiais didáticos, 
equipamentos e mobiliários ou adaptando os mesmos, reforma nas edificações, formação docente e demais frentes de atuação.

\section{Relação entre as universidades e a sociedade civil}

A importância da relação entre comunidade acadêmica e sociedade civil foi abordado anteriormente ao tratar do papel dos pilares da universidade na implementação de práticas inclusivas, com destaque ao eixo da extensão. Demonstrou-se que esse diálogo leva a construção e aprimoramento de atitudes, soluções e técnicas na educação inclusiva.

Portanto, é necessário somente evidenciar que a educação inclusiva acontece gradualmente; é uma área recente e está sendo desenvolvida por meio de reconhecimentos e demandas que estão aparecendo de acordo com a inserção das pessoas com deficiência em toda a sociedade. A participação e apoio consciente de grupos que não são envolvidos, de modo direto, com a causa se mostra relevante para que as pessoas com deficiência avancem com suas reivindicações e passem a ocupar e usufruir plenamente dos espaços públicos, em especial das universidades federais.

\section{Considerações finais}

O estudo apresentado buscou esclarecer princípios fundamentais da educação inclusiva e compreender como o acesso impulsionado pela Lei 13.409/2016 está mobilizando políticas e instrumentos de inclusão educacional nas universidades federais e quais são os obstáculos encontrados para a efetivação de tal política afirmativa.

A inclusão de pessoas com deficiência, detentores de necessidades especiais, no âmbito universitário, é gradativa, requer mudanças estruturais e administrativas da instituição, e igualmente demanda transformações na concepção das pessoas, que somente se concretizará com um intenso serviço relacionado a um trabalho de informação, conscientização, mobilização, que instrumente e efetue a realização de ações de respeito à diversidade e valorização das diferenças. A Lei $n^{0}$ 13.409/16 está provocando uma imposição na aceleração de tais processos nas instituições, resultando em uma não disposição de tempo para se preparar e atender os alunos com deficiência de forma exatamente apropriada no início, mas implica em um grande avanço com a democratização do acesso e força a produção de políticas voltadas a inclusão educacional. Vale apontar que as experiências adquiridas pela própria universidade com a entrada desses 
estudantes e as referências teóricas e práticas de universidades que possuem práticas consolidadas na área inclusiva resultarão em progressos significativos no processo de inclusão.

A educação inclusiva no nível superior, assim como em todos os outros níveis, pressupõe a participação ativa de toda a coletividade para a tomada de decisões em questões da sala de aula e da instituição, sendo necessários a flexibilidade na utilização dos recursos institucionais, humanos e materiais. É indispensável que todos os atores ligados a ações educacionais (alunos, professores, coordenadores e diretores) e a sociedade civil reconheçam e legitimem as diferentes encontradas nas salas de aula e colaborem na construção de condições de ensino e aprendizagem. 


\section{Referências Bibliográficas}

BRASIL. Decreto no 3.298, de 1999. Decreto $\mathbf{N}^{\circ}$ 3.298, de 20 de Dezembro de 1999. Brasília, Disponível em: http://www.planalto.gov.br/ccivil_03/decreto/d3298.htm. Acesso em: 14 de abril de 2019.

BRASIL. Lei $n^{\circ}$ 12.711, de 2012. Lei $\mathbf{N}^{\mathbf{0}}$ 12.711, de 29 de Agosto de 2012. Disponível em: http://www.planalto.gov.br/ccivil_03/_Ato2011-2014/2012/Lei/L12711.htm. Acesso em: 24 de fevereiro de 2019.

BRASIL. Lei $n^{\circ}$ 13.146, de 2016. Lei $\mathbf{N}^{\mathbf{0}}$ 13.146, de 6 de Julho de 2015. Brasília, Disponível em: http://www.planalto.gov.br/ccivil_03/_ato2015-2018/2015/lei/11314 6.htm. Acesso em: 14 de abril de 2019

BRASIL. Lei ${ }^{\circ}$ 13.409, de 2016. Lei $\mathbf{N}^{\mathbf{0}}$ 13.409, de 28 de Dezembro de 2016. Disponível em: http://www.planalto.gov.br/ccivil_03/_ato2015-2018/2016/lei/L13409.htm. Acesso em: 24 de fevereiro de 2019.

BUENO, J. G. Crianças com necessidades educativas especiais, política educacional e a formação de professores: generalistas ou especialistas. Revista Brasileira de Educação Especial, v. 3. n.5, 7-25, 1999.

CAMARGO, L. F.; SOFFA, M. M.; MARKOWICZ, D. Perspectivas sobre a educação inclusiva: um desafio possível. $2017 . \quad$ Disponível em: $<$ http://educere.bruc.com.br/arquivo/pdf2017/23527_11750.pdf $>$. Acesso em: 23 de março de 2019.

CAPELLINI, V. L. M. F.; RODRIGUES, O. M. P. R. Práticas inclusivas: fazendo a diferença. Rio de Janeiro: WAK Editora, 2014.

DIAS, S. M. B.; DA COSTA, S. L. A permanência no ensino superior e as estratégias institucionais de enfrentamento da evasão. Jornal de Políticas Educacionais, v. 9, n. 17/18, 2016.

FACHINETTI, T. A.; CARBONE CARNEIRO, R. U. A Tecnologia Assistiva como facilitadora no processo de inclusão: das políticas públicas a literatura. Revista on line de Política e Gestão Educacional, [S.1.], p. 1588-1597, dec. 2017.

FERRARI, M. A. L. D; SEKKEL, M. C. Educação inclusiva no ensino superior: um novo desafio. Psicologia: Ciência e Profissão, [s.1.], v. 27, n. 4, p.636-647, dez. 2007.

FERREIRA, S. L. Ingresso, permanência e competência: uma realidade possível para universitários com necessidades educacionais especiais. Revista Brasileira de Educação Especial, [s.1.], v. 13, n. 1, p.43-60, abr. 2007.

GLAT, R.; PLETSCH, M. D. O papel da universidade frente às políticas públicas para educação inclusiva. Revista Benjamin Constant, v. 29, n. 1, p. 3-8, 2004. 
GONÇALVES, A. G. Desempenho motor de alunos com paralisia cerebral frente à adaptação de recursos pedagógicos. 2010. 168p. Tese (Doutorado em Educação) - Faculdade de Filosofia e Ciências, Unesp de Marília.

GRUPO DE ESTUDOS MULTIDISCIPLINARES DA AÇÃO AFIRMATIVA (GEMAA) (Rio de Janeiro). O que são ações afirmativas? Disponível em: $<$ http://gemaa.iesp.uerj.br/o-que-saoacoes-afirmativas/>. Acesso em: 14 de abril de 2019.

MASCARO, C. A. A. de C. O atendimento pedagógico na sala de recursos sob o viés do plano educacional individualizado para o aluno com deficiência intelectual: um estudo de caso. 2017. 152 f. Tese (Doutorado em Educação) - Faculdade de Educação, Universidade do Estado do Rio de Janeiro, Rio de Janeiro, 2017.

MICHELS, L.R.F. A inclusão/exclusão da pessoa portadora de necessidades especiais no contexto universitário. 2000. Dissertação (Mestrado em Psicologia Social) - Pontifícia Universidade Católica do Rio Grande do Sul, Porto Alegre

MINISTÉRIO DA EDUCAÇÃO (MEC). Portaria No 3.284, de 7 de Novembro de 2003. Brasília, Disponível em: <http://portal.mec.gov.br/seesp/arquivos/pdf/port 3284.pdf >. Acesso em: 14 abr. 2019.

ORGANIZAÇÃO DAS NAÇÕES UNIDAS NO BRASIL (Brasília). Grupo de Trabalho da ONU sobre Afrodescendentes divulga comunicado final sobre visita ao Brasil. 2013. Disponível em: $<$ https://nacoesunidas.org/grupo-de-trabalho-da-onu-sobre-afrodescendentesdivulga-comunicado-final/>. Acesso em: 14 abr. 2019.

PLETSCH, M. D. A formação de professores para a educação inclusiva: legislação, diretrizes políticas e resultados de pesquisa. Educar em Revista, v. 25, n. 33, p. 143-156, 2008.

SASSAKI, R.K. Inclusão: a universidade e a pessoa com deficiência. Disponível em http: apacsp.com.br/site/interaja/mainUniversidade.htm. Acesso em: 23 de março de 2019.

SILVA, H. M. et al. A inclusão de estudantes com deficiência no ensino superior: revisão de literatura. Revista da Universidade Vale do Rio Verde, [s.1.], v. 10, n. 2, p.332-342, dez. 2012. Universidade Vale do Rio Verde (UninCor).

TOMELIN, K. N. et al. Educação inclusiva no ensino superior: desafios e experiências de um núcleo de apoio discente e docente. Rev. psicopedag., São Paulo, v. 35, n.106, p.94-103,2018. 